\section{Allogeneic hematopoietic cell transplantation with non-myeloablative conditioning for patients with hematologic malignancies: improved outcomes over two decades}

\author{
Jason P. Cooper, ${ }^{1,2}$ Barry E. Storer,,${ }^{1,2}$ Noa Granot, ${ }^{1}$ Boglarka Gyurkocza, ${ }^{1,2^{\circ}}$ \\ Mohamed L. Sorror, ${ }^{1,2}$ Thomas R. Chauncey, ${ }^{1,2,3}$ Judith Shizuru, ${ }^{4}$ \\ Georg-Nikolaus Franke, ${ }^{5}$ Michael B. Maris, ${ }^{6}$ Michael Boyer, ${ }^{7}$ \\ Benedetto Bruno, ${ }^{8}$ Firoozeh Sahebi, ${ }^{9}$ Amelia A. Langston, ${ }^{10}$ \\ Parameswaran Hari, ${ }^{11}$ Edward D. Agura,${ }^{12}$ Søren Lykke Petersen,,${ }^{13}$ \\ Richard T. Maziarz, ${ }^{14}$ Wolfgang Bethge, ${ }^{15}$ Julie Asch, ${ }^{16}$ Jonathan A. Gutman, ${ }^{17}$ \\ Gitte Olesen, ${ }^{18}$ Andrew M. Yeager, ${ }^{19}$ Kai Hübel, ${ }^{20}$ William J. Hogan, ${ }^{21}$ \\ David G. Maloney, ${ }^{1,2}$ Marco Mielcarek, ${ }^{1,2}$ Paul J. Martin, ${ }^{1,2}$ \\ Mary E. D. Flowers, ${ }^{1,2}$ George E. Georges, ${ }^{1,2}$ Ann E. Woolfrey, ${ }^{1,2}$ \\ H. Joachim Deeg, ${ }^{1,2}$ Bart L. Scott, ${ }^{1,2}$ George B. McDonald, ${ }^{1,2}$ Rainer Storb ${ }^{1,2}$ \\ and Brenda M. Sandmaier ${ }^{1,2}$ \\ ${ }^{1}$ Fred Hutchinson Cancer Research Center, Seattle, WA, USA; ${ }^{2}$ University of Washington, \\ Seattle, WA, USA; ${ }^{3}$ Veterans Affairs Puget Sound Health Care System, Seattle, WA, USA; \\ ${ }^{4}$ Stanford University, Palo Alto, CA, USA; ${ }^{5}$ University of Leipzig, Leipzig, Germany; \\ ${ }^{6}$ Colorado Blood Cancer Institute at HealthONE Presbyterian/St. Luke Medical Center, \\ Denver, CO, USA; ${ }^{7}$ University of Utah, Salt Lake City, UT, USA; ${ }^{8}$ University of Turin, Turin, \\ Italy; ${ }^{9}$ City of Hope/Kaiser Permanente Medical Group, Duarte, CA, USA; ${ }^{10}$ Winship \\ Cancer Institute at Emory University, Atlanta, GA, USA; ${ }^{11}$ Medical College of Wisconsin, \\ Milwaukee, WI, USA; ${ }^{12}$ Baylor University, Dallas, TX, USA; ${ }^{13}$ University of Copenhagen \\ Rigshospitalet, Copenhagen, Denmark; ${ }^{14}$ Oregon Health and Science University, \\ Portland, OR, USA; ${ }^{15}$ University of Tübingen, Tübingen, Germany; ${ }^{16}$ LDS Hospital, Salt \\ Lake City, UT, USA; ${ }^{17}$ University of Colorado, Denver, CO, USA; ${ }^{18}$ Aarhus University, \\ Aarhus, Denmark; ${ }^{19}$ University of Arizona Cancer Center, Tucson, AZ, USA; ${ }^{20}$ University \\ Hospital of Cologne, Cologne, Germany and ${ }^{21}$ Mayo Clinic, Rochester, MN, USA
}

${ }^{\circ}$ Current address: Memorial Sloan Kettering Cancer Center and Weill Cornell Medical College, New York, NY, USA.

\section{ABSTRACT}

W Te have used a non-myeloablative conditioning regimen for allogeneic hematopoietic cell transplantation for the past 20 years. During that period, changes in clinical practice have been aimed at reducing morbidity and mortality from infections, organ toxicity, and graft-versus-host disease. We hypothesized that improvements in clinical practice led to better transplantation outcomes over time. From 1997-2017, 1,720 patients with hematologic malignancies received low-dose total body irradiation \pm fludarabine or clofarabine before transplantation from HLAmatched sibling or unrelated donors, followed by mycophenolate mofetil and a calcineurin inhibitor \pm sirolimus. We compared outcomes in three cohorts by year of transplantation: 1997-2003 $(n=562), 2004-2009(n=594)$, and $2010-2017(n=564)$. The proportion of patients $\geq 60$ years old increased from $27 \%$ in $1997-2003$ to $56 \%$ in $2010-2017$, and with scores from the Hematopoietic Cell Transplantation Comorbidity Index of $\geq 3$ increased from $25 \%$ in $1997-2003$ to $45 \%$ in $2010-2017$. Use of unrelated donors increased from $34 \%$ in $1997-2003$ to $65 \%$ in $2010-2017$. When outcomes from 2004-2009 and 2010-2017 were compared to 1997-2003, improvements were noted in overall survival $(P=0.0001$ for $2004-2009$ and $P \leq 0.0001$ for 2010-2017), progression-free survival ( $P=0.002$ for 2004-2009 and $P<0.0001$ for $2010-2017)$, non-relapse mortality $(P<0.0001$ for 2004 2009 and $P<0.0001$ for 2010-2017), and in rates of grades $2-4$ acute and chronic graft-versus-host disease. For patients with hematologic malignancies who underwent transplantation with non-myeloablative conditioning, outcomes have improved during the past two decades. Trials reported are registered under clinicaltrials gov. Identifiers: NCT00003145,
Ferrata Storti Foundation

Haematologica 2021

Volume 106(6):1599-1607

\section{Correspondence:}

JASON P. COOPER

jpcooper@fredhutch.org

Received: January 27, 2020.

Accepted: May 27, 2020.

Pre-published: June 4, 2020.

https://doi.org/10.3324/haematol.2020.248187

(C)2021 Ferrata Storti Foundation

Material published in Haematologica is covered by copyright. All rights are reserved to the Ferrata Storti Foundation. Use of published material is allowed under the following terms and conditions:

https://creativecommons.org/licenses/by-nc/4.0/legalcode. Copies of published material are allowed for personal or internal use. Sharing published material for non-commercial purposes is subject to the following conditions:

https://creativecommons.org/licenses/by-nc/4.0/legalcode, sect. 3. Reproducing and sharing published material for commercial purposes is not allowed without permission in writing from the publisher. 


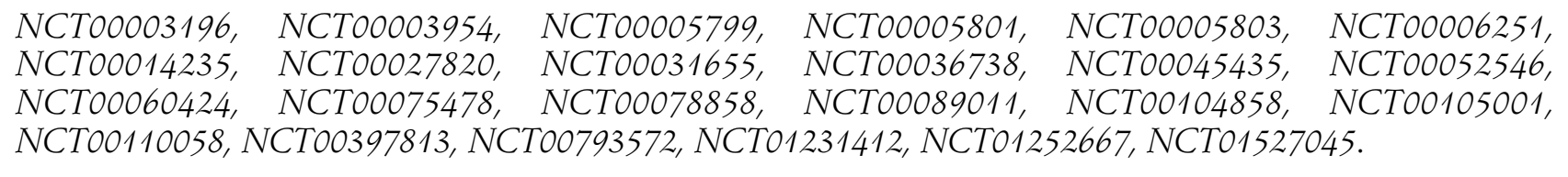

\section{Introduction}

In 1997 we introduced a minimally intensive conditioning regimen for allogeneic hematopoietic cell transplantation (HCT) that enabled treating elderly and medically infirm younger patients with advanced hematologic malignancies in the outpatient setting. We previously reported outcomes for patients who underwent HCT from 1997-2009 using this regimen, which included lowdose total body irradiation (TBI) with or without fludarabine. ${ }^{1}$ Five-year overall survival ranged from $25 \%$ to $60 \%$ (depending on disease type, comorbidities, and graft-versus-host disease [GvHD]), non-relapse mortality (NRM) was $24 \%$, and relapse-related mortality was $35 \%$. The most significant contributor to NRM was GvHD.

Between 1997 and 2017 a number of changes in clinical practice were introduced that were aimed at improving HCT outcomes including reductions in the use of systemic glucocorticoids as treatment for acute $\mathrm{GvHD}^{2,3}$ use of ursodiol to reduce hepatic complications, ${ }^{4,5}$ addition of sirolimus for control of GvHD, ${ }^{6-8}$ use of fluoroquinolones for antibacterial prophylaxis during periods of neutropenia, ${ }^{9-11}$ use of more mold-active azoles for antifungal prophylaxis, ${ }^{12,13}$ and initiation of pre-emptive antiviral therapy based on more sensitive polymerase chain reaction (PCR)based cytomegalovirus (CMV) diagnostic testing. ${ }^{14-16}$

During the same time period, patient and donor characteristics as well as indications for HCT also changed. The proportion of patients older than 60 years increased from $27 \%$ to $56 \%$, proportion of patients with hematopoietic cell transplantation-comorbidity index (HCT-CI $)^{17}$ scores $\geq 3$ increased from $25 \%$ to $45 \%$, use of unrelated donors increased from $35 \%$ to $65 \%$, and increasing numbers of patients underwent HCT for acute myeloid leukemia (AML) while decreasing numbers of patients underwent HCT for multiple myeloma and chronic myelogenous leukemia (CML). The current study analyzed whether benefits associated with the changes in clinical care for patients undergoing HCT outweighed the adverse outcomes expected from older patient age, increased comorbidities, and greater use of unrelated donors. To that end, we compared outcomes in three cohorts of patients by year of HCT: 1997-2003, 2004-2009, and 2010-2017.

\section{Methods}

\section{Patients}

Between December 16, 1997 and June 30, 2017, 1,720 consecutive patients with hematologic malignancies underwent HCT at the Fred Hutchinson Cancer Research Center (FHCRC) or collaborating centers. We included patients who were entered onto prospective clinical trials registered with clinicaltrials.gov at both FHCRC and collaborating centers (Online Supplementary Table S1), and patients transplanted outside of prospective trials at FHCRC. This study was approved by the Institutional Review Board (IRB) at FHCRC and all patients signed IRB-approved consents.

\section{Graft source, conditioning, and post-engraftment immunosuppression}

All patients received unmodified grafts consisting of granulocyte colony-stimulating factor (GCSF)-mobilized peripheral blood stem cells (PBSC). Donors and recipients were matched at HLA-A, $-B,-C,-D R B 1$, and -DOB1 by high-resolution typing except for 104 unrelated donor-recipient pairs who were mismatched at the level of one HLA class I allele. Conditioning regimens and immunosuppression to aid engraftment and control GvHD are summarized in the Online Supplementary Table S1.

\section{Clinical endpoints}

Patients had bone marrow aspirations to assess disease status on days 28,84 , and 365 after HCT, and otherwise as clinically indicated. Acute and chronic GvHD were diagnosed and graded as previously described. ${ }^{18,19}$ Relapse was defined as recurrence of malignancy based on imaging, marrow morphology, flow cytometry, cytogenetics, and/or disease-specific molecular markers. Progression was defined as $\geq 50 \%$ increase in disease burden. ${ }^{20}$ Relapse-related mortality included deaths after relapse or progression of disease present before HCT, regardless of other events. NRM included deaths in the absence of relapse or progression.

\section{Clinical assessment of organ complications and infections through day $\mathbf{1 0 0}$}

Liver injury was assessed according to peak bilirubin concentration. ${ }^{19}$ Acute kidney injury was defined as a serum creatinine concentration that was at least 2-fold higher than the baseline value. ${ }^{21}$ CMV infection was defined as the presence of pp65 antigen or DNA in plasma, ${ }^{22}$ and CMV disease was defined as dysfunction of an organ infected by $\mathrm{CMV}^{23}$ One or more positive blood cultures for gram-negative bacteria were defined as gram-negative bacteremia; gram-negative organisms tend to cause the most serious infections in patients who are neutropenic after $\mathrm{HCT}^{24}$ Invasive fungal infections were defined according to consensus criteria and included cases deemed proven or probable. ${ }^{25}$

\section{Statistical analysis}

Overall survival (OS) and progression-free survival (PFS) were estimated using the Kaplan-Meier method. Rates of acute and chronic GvHD, relapse or progression, and NRM were estimated according to standard methods. ${ }^{26}$ Death was treated as a competing risk factor for all other time-to-event endpoints. Relapse was treated as a competing risk for NRM. Relapse-related mortality refers to survival after relapse among patients that relapsed. Multivariate Cox regression analysis of cause-specific hazards, stratified by center, was used for adjusted comparisons between groups defined by year of HCT. Adjusted estimates of survival and cumulative incidence were based on methods previously described. ${ }^{27}$ Briefly, the adjusted curves represent the hypothetical outcomes for the three transplant eras if each era had the patient characteristics of the first era, based on results from the adjusted Cox regression models. Multivariate logistic regression was used for adjusted comparisons of rates of elevated bilirubin and creatinine. The adjusted models included the following variables that varied over era of HCT and were potentially related to one or more endpoints: treatment type (on-protocol, off-protocol); age $(\leq 49,50-59$, or $\geq 60$ years); disease relapse risk (low, standard, 
high); multiple myeloma diagnosis; AML diagnosis; CMV serostatus (recipient and donor negative, recipient and/or donor positive); donor relation (related, unrelated); sex mismatch (female to male, others); prior HCT (no, yes); HLA-allele mismatch (no, yes); HCTCI $(0,1-2,3, \geq 4$, or missing). All $P$-values were two-sided and are unadjusted for multiple comparisons.

\section{Results}

\section{Study population}

Our study population of 1,720 total patients in three tertiles is summarized in Table 1 and consisted of 562 patients who underwent HCT during the period from

Table 1. Transplant and patient characteristics by transplant era.

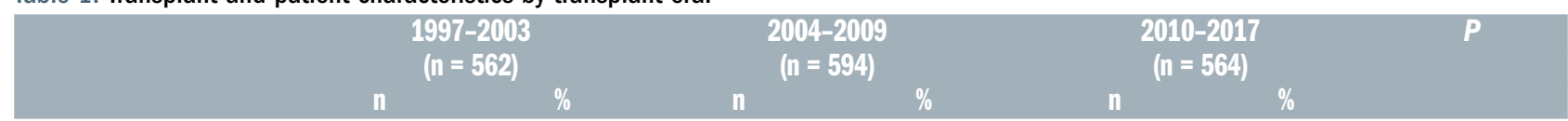

\section{Transplant characteristics}

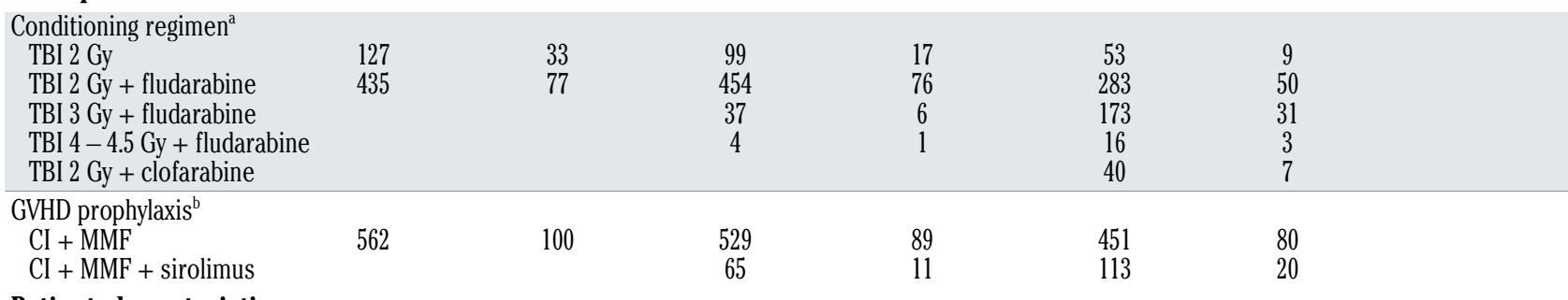

\section{Patient characteristics}

\begin{tabular}{|c|c|c|c|c|c|c|c|}
\hline $\begin{array}{l}\text { Center / treatment }^{\mathrm{c}} \\
\text { Non-FH on-protocol } \\
\text { FH on-protocol } \\
\text { FH off-protocol }\end{array}$ & $\begin{array}{c}287 \\
264 \\
11\end{array}$ & $\begin{array}{c}51 \\
47 \\
2\end{array}$ & $\begin{array}{c}208 \\
327 \\
59\end{array}$ & $\begin{array}{l}35 \\
55 \\
10\end{array}$ & $\begin{array}{l}130 \\
333 \\
101\end{array}$ & $\begin{array}{l}23 \\
59 \\
18\end{array}$ & $<0.0001$ \\
\hline $\begin{array}{l}\text { Diagnosis } \\
\text { ALL } \\
\text { AML } \\
\text { CLL } \\
\text { CML } \\
\text { HL } \\
\text { MDS / MPN } \\
\text { MM } \\
\text { NHL } \\
\text { WM }\end{array}$ & $\begin{array}{c}17 \\
90 \\
62 \\
39 \\
34 \\
84 \\
129 \\
101 \\
6\end{array}$ & $\begin{array}{c}3 \\
16 \\
11 \\
7 \\
6 \\
15 \\
22 \\
18 \\
1\end{array}$ & $\begin{array}{c}30 \\
184 \\
65 \\
12 \\
30 \\
71 \\
95 \\
101 \\
6\end{array}$ & $\begin{array}{c}5 \\
31 \\
11 \\
2 \\
5 \\
12 \\
16 \\
17 \\
1\end{array}$ & $\begin{array}{c}45 \\
167 \\
73 \\
6 \\
17 \\
90 \\
56 \\
107 \\
2\end{array}$ & $\begin{array}{c}8 \\
30 \\
13 \\
1 \\
3 \\
16 \\
10 \\
19 \\
<1\end{array}$ & $<0.0001$ \\
\hline $\begin{array}{l}\text { Donor }^{\mathrm{d}} \\
\text { Related } \\
\text { Unrelated }\end{array}$ & $\begin{array}{l}371 \\
191\end{array}$ & $\begin{array}{l}66 \\
34\end{array}$ & $\begin{array}{l}249 \\
345\end{array}$ & $\begin{array}{l}42 \\
58\end{array}$ & $\begin{array}{l}197 \\
367\end{array}$ & $\begin{array}{l}35 \\
65\end{array}$ & $<0.0001$ \\
\hline $\begin{array}{l}\text { Disease risk group } \\
\text { Low } \\
\text { Standard } \\
\text { High }\end{array}$ & $\begin{array}{l}129 \\
270 \\
163\end{array}$ & $\begin{array}{l}23 \\
48 \\
29\end{array}$ & $\begin{array}{l}131 \\
297 \\
166\end{array}$ & $\begin{array}{l}22 \\
50 \\
28\end{array}$ & $\begin{array}{l}169 \\
276 \\
118\end{array}$ & $\begin{array}{l}30 \\
49 \\
21\end{array}$ & 0.002 \\
\hline $\begin{array}{l}\text { Age, years } \\
\quad \leq 49 \\
50-59 \\
\geq 60\end{array}$ & $\begin{array}{l}174 \\
236 \\
152\end{array}$ & $\begin{array}{l}31 \\
42 \\
27\end{array}$ & $\begin{array}{l}131 \\
208 \\
255\end{array}$ & $\begin{array}{l}22 \\
35 \\
43\end{array}$ & $\begin{array}{l}102 \\
147 \\
316\end{array}$ & $\begin{array}{l}18 \\
26 \\
56\end{array}$ & $<0.0001$ \\
\hline $\begin{array}{l}\text { Sex match } \\
\text { Female to male } \\
\text { Others }\end{array}$ & $\begin{array}{l}169 \\
393\end{array}$ & $\begin{array}{l}30 \\
70\end{array}$ & $\begin{array}{l}137 \\
457\end{array}$ & $\begin{array}{l}23 \\
77\end{array}$ & $\begin{array}{l}141 \\
423\end{array}$ & $\begin{array}{l}25 \\
75\end{array}$ & 0.04 \\
\hline $\begin{array}{l}\text { CMV serostatus } \\
\text { R-/D- } \\
\text { R+/D- } \\
\text { R+/D+ } \\
\text { R-/D+ }\end{array}$ & $\begin{array}{c}129 \\
141 \\
84 \\
208\end{array}$ & $\begin{array}{l}23 \\
25 \\
15 \\
37\end{array}$ & $\begin{array}{l}172 \\
172 \\
73 \\
177\end{array}$ & $\begin{array}{l}29 \\
29 \\
12 \\
30\end{array}$ & $\begin{array}{l}169 \\
158 \\
68 \\
169\end{array}$ & $\begin{array}{l}30 \\
28 \\
12 \\
30\end{array}$ & 0.02 \\
\hline $\begin{array}{l}\text { HCT-CI } \\
0 \\
1,2 \\
3 \\
\geq 4 \\
\text { Missing }\end{array}$ & $\begin{array}{l}118 \\
129 \\
73 \\
67 \\
174\end{array}$ & $\begin{array}{l}21 \\
23 \\
13 \\
12 \\
31\end{array}$ & $\begin{array}{l}89 \\
137 \\
131 \\
125 \\
113\end{array}$ & $\begin{array}{l}15 \\
23 \\
22 \\
21 \\
19\end{array}$ & $\begin{array}{c}56 \\
152 \\
113 \\
141 \\
102\end{array}$ & $\begin{array}{l}10 \\
27 \\
20 \\
25 \\
18\end{array}$ & $<0.0001$ \\
\hline $\begin{array}{l}\text { HLA-allele mismatch } \\
\text { No } \\
\text { Yes }\end{array}$ & $\begin{array}{c}534 \\
28\end{array}$ & $\begin{array}{c}95 \\
5\end{array}$ & $\begin{array}{c}552 \\
42\end{array}$ & $\begin{array}{c}93 \\
7\end{array}$ & $\begin{array}{c}530 \\
34\end{array}$ & $\begin{array}{c}94 \\
6\end{array}$ & 0.72 \\
\hline $\begin{array}{l}\text { Prior HCTh } \\
\text { No } \\
\text { Yes }\end{array}$ & $\begin{array}{l}427 \\
135\end{array}$ & $\begin{array}{l}76 \\
24\end{array}$ & $\begin{array}{l}416 \\
179\end{array}$ & $\begin{array}{l}70 \\
30\end{array}$ & $\begin{array}{l}433 \\
131\end{array}$ & $\begin{array}{l}77 \\
23\end{array}$ & 0.008 \\
\hline
\end{tabular}


TBI: total body irradiation; Gy: Gray; GvHD: graft-versus-host disease; Cl: calcineurin inhibitor; MMF: mycophenolate mofetil; FH: Fred Hutchinson Cancer Research Center; ALL: acute lymphoblastic leukemia;AML: acute myeloid leukemia; CLL: chronic lymphocytic leukemia; CML: chronic myelogenous leukemia; HL: Hodgkin lymphoma; MDS: myelodysplastic syndromes; MPN: myeloproliferative neoplasms; MM: multiple myeloma; NHL: non-Hodgkin lymphoma; WM:Waldenström macroglobulinemia; CMV: cytomegalovirus; R: recipient; D: donor; HCT-CI: hematopoietic cell transplantation comorbidity index; GCSF: granulocyte colony-stimulating factor; PBSC: peripheral blood stem cells. ${ }^{\mathrm{F}}$ Fludarabine was given at a dose of $30 \mathrm{mg} / \mathrm{m}^{2} /$ day IV on days 4,3 , and 2 before HCT. Clofarabine was given at a dose of $30-50 \mathrm{mg} / \mathrm{m}^{2} /$ day on days $6,5,4,3$, and 2 before HCT.TBI was given on

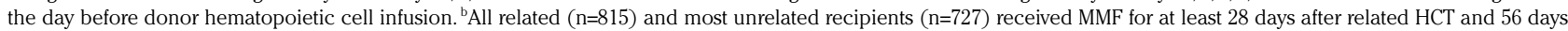
after unrelated HCT, with either cyclosporine or tacrolimus, for at least 80 days, with the majority of patients receiving a calcineurin inhibitor for $150-180$ days after HCT. The remaining unrelated recipients ( $\mathrm{n}=178$ total - zero during 1997-2003, 65 during 2004-2009, and 113 during 2010-2017) received sirolimus from day -3 to either day 80 or 180, in addition to MMF (days zero to 40 or 96 ) and cyclosporine (days -3 to 150-180). ${ }^{c}$ On-protocol patients were those transplanted on active clinical trials. Off-protocol patients were those transplanted outside of an active clinical study. All patients signed consent giving permission for their clinical data to be used for research studies such as this one. ${ }^{\mathrm{d} G C S F}$ mobilized PBSC grafts contained a median of $8.0 \times 10^{6} \mathrm{CD}^{+} 4^{+}$cells $/ \mathrm{kg}$ (range, $0.2-42.6 \times 10^{6} \mathrm{CD}^{+} 4^{+} \mathrm{cells} / \mathrm{kg}$ ) and $3.1 \times 10^{8} \mathrm{CD}^{+}$cells $/ \mathrm{kg}\left(\mathrm{range}, 0.1-296.0 \times 10^{8} \mathrm{CD} 3^{+}\right.$cells $/ \mathrm{kg}$ ). ${ }^{\mathrm{e}} \mathrm{Kahl}$ disease risk groups assigned as described. ${ }^{20} \mathrm{H}$ Hematopoietic cell transplantation comorbidity index (HCT-CI) assigned as described ${ }^{17} \mathrm{~g}$ Donors and recipients were matched at HLAA, - B, - C, -DRB1, and -DQB1 by high-resolution typing except for the specified number of unrelated donor-recipient pairs who were mismatched at the level of one HLA class I allele. 'Includes planned autologous, failed autologous, and failed allogeneic transplantation. The number of patients who had a prior planned autologous HCT decreased from 107 (19\%) during 1997-2003 to one during 2010-2017; 23 patients (4\%) had an unsuccessful prior autologous HCT during 1997-2003, increasing to 120 patients (21\%) during 2010-2017; 3 patients (<1\%) had an unsuccessful prior allogeneic HCT during 1997-2003, increasing to 22 patients (4\%) during 2010-2017. ${ }^{i}$-values reflect any pattern of variation over the three time periods, including trends over time.

1997-2003, 594 from 2004-2009, and 564 from 20102017. An increasing number and proportion of patients underwent HCT at FHCRC over time $(P<0.0001)$ on protocols considered standard-of-care. The proportion of patients age $\geq 60$ years at the time of HCT increased, as did the proportion of patients with an HCT-CI score $\geq 3$. Unrelated donors were utilized more frequently over time. The distribution of diagnoses changed over time $(P<0.0001)$, most notably with an increase in the proportion of patients with AML (16\% during 1997-2003 and $30 \%$ during 2010-2017) and decreases in CML and multiple myeloma.

The distribution of disease relapse risk groups 20 changed over time $(P<0.0001)$, with a decreasing proportion of patients with high-risk disease and an increasing proportion with low-risk disease.

A minority of patients had a prior HCT, but the types of prior HCT changed over time. The number of patients who had a prior planned autologous HCT decreased from 107 (19\%) during 1997-2003 to one during 2010-2017, while the number of patients who had unsuccessful prior autologous or allogeneic HCT increased (Table 1). Planned autologous HCT were typically performed in conjunction with a tandem allogeneic HCT for patients with multiple myeloma.

\section{Major endpoints by era of transplant}

Associations of major endpoints with the time period of HCT are summarized in Table 2 and Figures 1 and 2. As described in the Methods section, results were adjusted for risk factors that varied over the three time periods and were potentially related to one or more endpoints of interest. OS, PFS, and NRM all had a significant association with the era of HCT. When compared to 1997-2003, significant improvements were noted during $2004-2009$ and 2010-2017 for OS (hazard ratio [HR] 0.72, $P=0.0001$ and HR 0.60, $P<0.0001$ ), PFS (HR 0.78, $P=0.002$ and HR 0.63, $P<0.0001$ ), and NRM (HR $0.58, P<0.0001$ and HR 0.52, $P<0.0001)$. The risk of relapse or progression was lower during 2010-2017 when compared to 1997-2003 (HR $0.71, P=0.006$ ). The incidence of relapse-related mortality trended toward improvement in later time periods, but the differences from 1997- 003 were not statistically significant.

Rates of grades 2-4 acute GvHD, grades 3-4 acute GvHD, and chronic GvHD were all significantly associated with time period of HCT and, when compared to 1997-2003, all improved significantly during 2004-2009 and 2010-2017. Given we increasingly used 'triple immunosuppression' consisting of MMF, a calcineurin inhibitor, and sirolimus for patients undergoing HCT from unrelated donors, ${ }^{6,8}$ we evaluated its impact on acute GvHD separately. Adding sirolimus reduced the rates of grades 2-4 and 3-4 acute GvHD when compared to patients who received $\mathrm{MMF}$ and a calcineurin inhibitor without sirolimus (HR 0.52, 95\% CI: 0.40-0.67, $P<0.0001$ and HR 0.54, 95\% CI: $0.29-1.01, P=0.05$, respectively).

\section{Association of relapse or progression with era of transplant in patients with acute myeloid leukemia in remission}

Since the overall rate of relapse or progression was significantly decreased in the most recent time period, we evaluated whether this was also true for the 351 patients with AML in first or second complete remission (CR1/CR2): 64 during 1997-2003, 147 during 2004-2009, and 140 during 2010-2017. Among these patients, measurable (minimal) residual disease (MRD) at the time of HCT as determined by flow cytometry, cytogenetics, or molecular analysis was detected in 16 patients $(11 \%)$ during 2004- 2009 and 32 patients (23\%) during 2010-2017. Data were unavailable prior to 2004 . We found no statistically significant change in the rate of relapse for patients with AML in CR1/CR2 over time. When compared to 1997-2003, the adjusted HR for relapse during 2004-2009 was 0.84 (95\% CI: $0.4-1.6, P=0.61)$ and during 2010-2017 was 0.89 (95\% CI: $0.4-1.8, P=0.75)$.

\section{Associations of organ complications and infections with era of transplant}

Associations of liver and kidney injuries, gram-negative bacteremia, invasive fungal infections, and CMV infection with era of HCT are shown in Table 3. Compared to 1997-2003, the incidences of patients having liver or kidney complications, gram-negative bacteremia, or an invasive fungal infection through day 100 were significantly lower in the two most recent time periods of HCT.

Serologic CMV infection was evaluated in recipients who were seropositive at the time of HCT as these patients were at the highest risk for development of CMV disease and $\mathrm{CMV}$-associated mortality. ${ }^{28} \mathrm{CMV}$ diagnostic testing evolved during the three time periods, and we included measurement via both the pp65 antigen detection assay and PCR-based detection of CMV DNA in plas$\mathrm{ma}$ in our analysis. While the incidence of CMV reactivation did not significantly change over time, the incidence of CMV disease was significantly decreased in the most recent era $(P=0.001)$. 
A
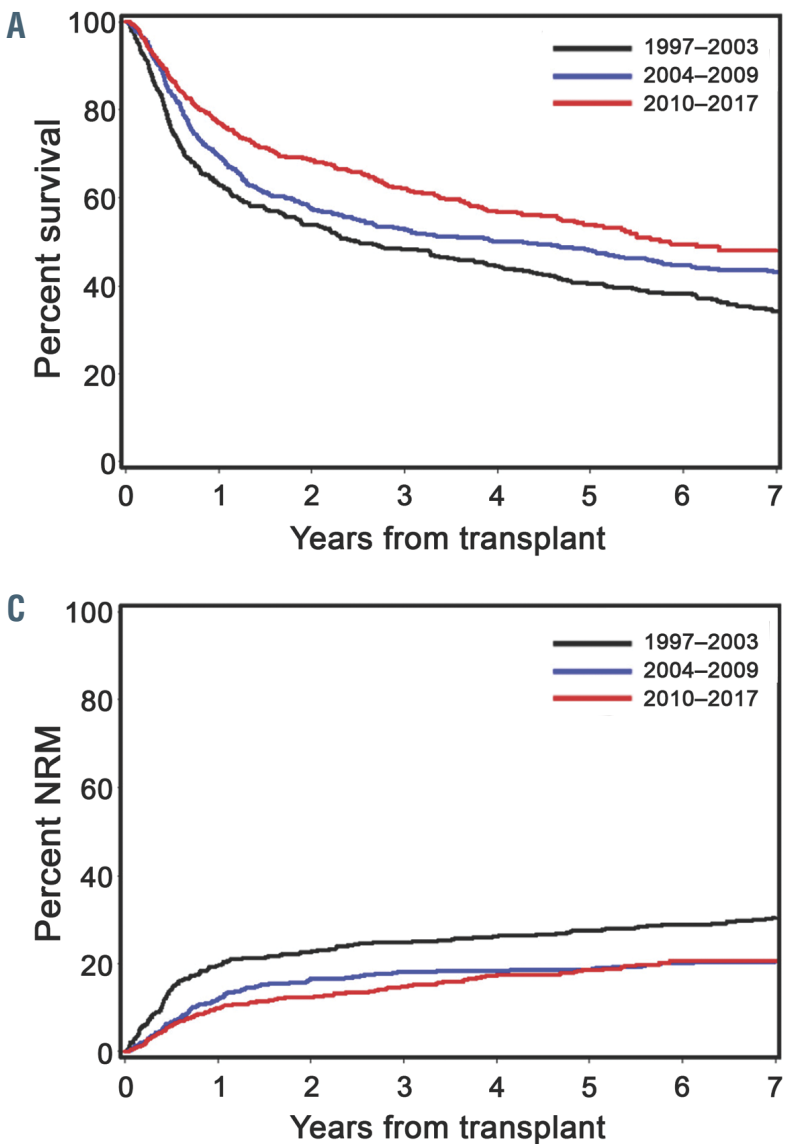
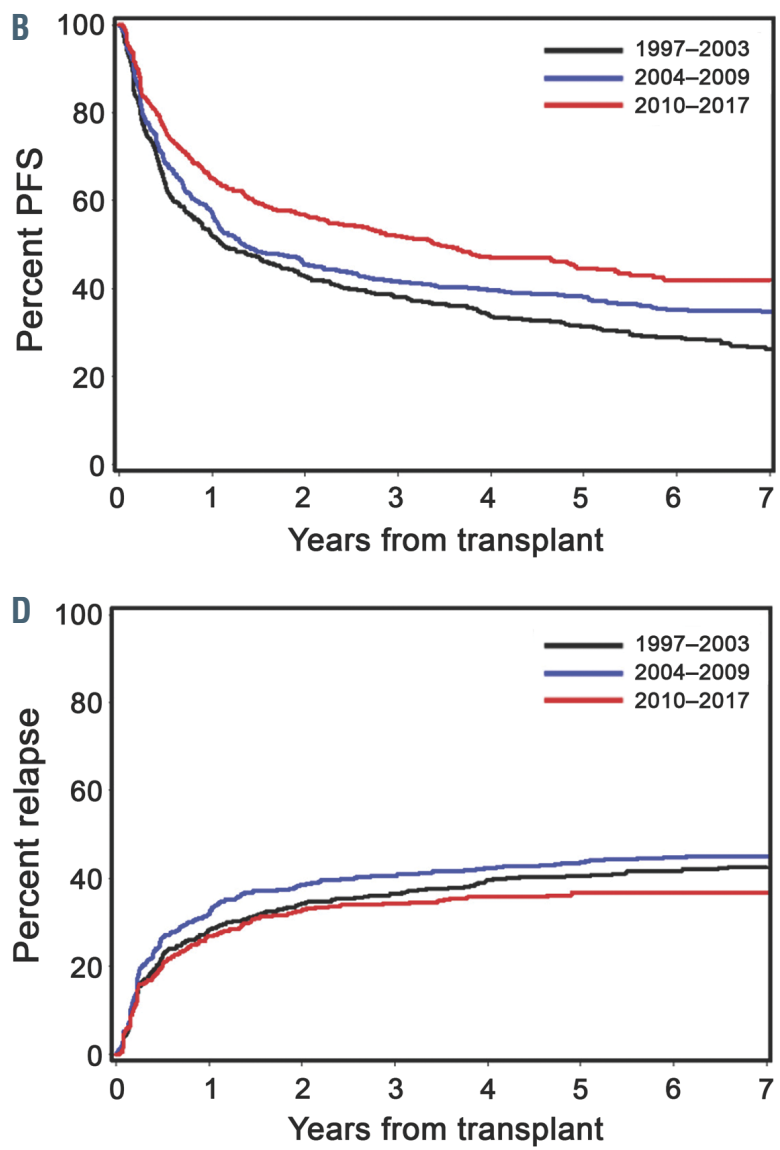

Figure 1. Adjusted cumulative incidence rates of major clinical endpoints by era of transplant. (A) Overall survival, (B) progression-free survival (PFS), (C) nonrelapse mortality (NRM), and (D) relapse. Era of transplant: 1997-2003 (black line), 2004-2009 (blue line), and 2010-2017 (red line).

\section{Comparison of endpoints in two most recent transplant eras}

Comparisons of clinical endpoints and in the incidences of organ complications and infections in the most recent transplant era (2010-2017) to those in 2004-2009 are shown in the Online Supplementary Tables S2 and S3. OS, PFS, relapse rate, and the rate of grades 2-4 acute GvHD significantly improved in the most recent era as compared to 2004-2009. Over this same time period, significant improvements were also noted in the incidences of gramnegative bacteremias, invasive fungal infections, and in CMV antigenemia and disease.

\section{Discussion}

Over the period from 1997-2017, we found marked improvements in OS, PFS, NRM, and in the rates of acute and chronic GvHD after HCT with non-myeloablative conditioning. We also noted a trend toward reduced relapse-related mortality. During this same time period, patient age and burden of comorbidity at the time of HCT increased, higher proportions received grafts from unrelated donors, and AML became the leading indication for HCT, while the numbers of patients with multiple myeloma and CML declined. Consistent with these shifts in diagnoses, there was a decrease in patients who underwent HCT after a prior planned autologous transplanta- tion, which is likely related to the decrease in multiple myeloma as an indication (decreased use of planned tandem autologous-allogeneic transplantation), ${ }^{29}$ and increases in prior unsuccessful autologous HCT for non-Hodgkin lymphoma and prior unsuccessful allogeneic HCT for AML. These data underscore the fact that non-myeloablative conditioning has been increasingly recognized as an option for patients with recurrent hematologic malignancies after prior HCT with high-intensity conditioning regimens. ${ }^{30}$ Interestingly we did not see an increase in the number of patients with MDS who underwent HCT, despite the increasing recognition of MDS-associated mortality risk and life expectancy benefit of HCT for patients with high-risk MDS. ${ }^{31,32}$ We suspect that this lack of increase in MDS patients may be due to referral patterns from providers who are unaware that HCT is a therapeutic option for their MDS patients who are older or medically infirm.

The substantial reduction in NRM, lower risk of relapse seen primarily in the most recent cohort, and modest improvement in relapse-related mortality all contributed to increased overall survival. Contributors to the improvement in NRM over time are summarized in Table 4 and include the reductions seen in liver and kidney complications; decreases in incidences of gram-negative bacteremia, invasive fungal infections, and CMV disease; and reduced rates of acute and chronic GvHD. We speculate that several changes in clinical practice contributed to the 
Table 2. Association of transplant era with major endpoints.

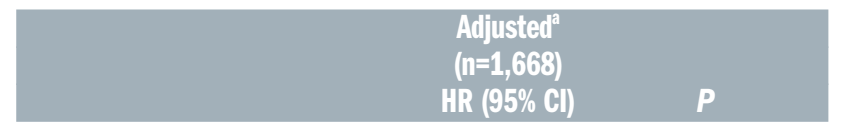

Overall survival

$1997-2003$

$2004-2009$

$2010-2017$

1.0

$0.72(0.6-0.9) \quad 0.0001$

$0.60(0.5-0.7) \quad<0.0001$

Progression-free survival

$1997-2003$

$2004-2009$

1.0

$2010-2017$

$0.78(0.7-0.9) \quad 0.002$

$0.63(0.5-0.8) \quad<0.0001$

Relapse/progression

$1997-2003$

$2004-2009$

$2010-2017$

1.0

$0.93(0.8-1.1) \quad 0.52$

$0.71(0.6-0.9)$

0.006

Non-relapse mortality

$1997-2003$

2004-2009

1.0

$2010-2017$

$0.58(0.5-0.7)$

$0.52(0.4-0.7)$

$<0.0001$

Relapse-related mortality

$1997-2003$

$2004-2009$

$2010-2017$

1.0

$0.85(0.7-1.1) \quad 0.15$

$0.80(0.6-1.0)$

0.10

Acute GvHD grade 2-4

$1997-2003$

$2004-2009$

1.0

2010-2017

$0.81(0.7-1.0)$

$0.64(0.5-0.8)$

0.03

Acute GvHD grade 3-4

$1997-2003$

$2004-2009$

$2010-2017$

1.0

$0.67(0.5-1.0)$

$0.54(0.4-0.8)$

0.03

Chronic GvHD

$1997-2003$

$2004-2009$

$2010-2017$

1.0

$\begin{array}{ll}0.59(0.5-0.7) & <0.0001 \\ 0.57(0.5-0.7) & <0.0001\end{array}$

HR: hazard ratio; Cl: confidence interval; GvHD: graft-versus-host disease; MM: multiple myeloma;AML: acute myeloid leukemia; CMV: cytomegalovirus; R: recipient; D: donor; HCT: hematopoietic cell transplantation; HCT-CI: hematopoietic cell transplantation

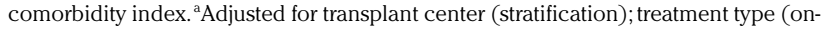
protocol, off-protocol), age ( $\leq 49,50-59, \geq 60$ years); disease risk group (low, standard, high); MM diagnosis;AML diagnosis; CMV ( $\mathrm{R}-$ and $\mathrm{D}-, \mathrm{R}+$ or $\mathrm{D}+$ ); donor relation (related, unrelated); sex mismatch (female to male, others); prior HCT (no, yes); allele mismatch (no, yes); HCT-CI (0, 1-2, 3, $\geq 4$, missing). Kahl disease risk groups and HCT-Cl assigned as described. ${ }^{17,20}{ }^{\mathrm{b}}$ Relapse-related mortality refers to survival after relapse among patients that relapsed.

reduction in NRM. Topically-active glucocorticoids such as beclomethasone dipropionate were introduced which, when given with prednisone to patients with gastrointestinal GvHD in a randomized, placebo-controlled trial, allowed for a rapid taper of prednisone dosing starting 10 days after initiation, significantly reduced the risk of GvHD-treatment failure, and reduced the risk of mortality by $37 \%$ after a median follow-up of 3.6 years. ${ }^{3}$ Decreases in the use of systemic glucocorticoids for treatment of acute GvHD, along with the addition of sirolimus to MMF with a calcineurin inhibitor as GvHD prophylaxis have also resulted in lower rates of fungal infections ${ }^{2}$ and $\mathrm{CMV}$ reactivation ${ }^{6,8}$ Changes in infection prophylaxis also likely contributed to reductions in NRM. This included a shift in antibacterial prophylaxis from cephalosporins to fluoroquinolones during periods of neutropenia, ${ }^{9-11}$ a shift in antifungal prophylaxis from fluconazole to extendedspectrum triazoles (itraconazole, voriconazole, posaconazole) with greater activity against mold, ${ }^{12,13}$ empirical anti-

Table 3. Association of transplant era with incidences of organ complications and infections.

Organ Toxicity $(n=1,548) \quad$ OR $(95 \%$ Cl) $\quad P$
Bilited

Bilirubin $>4 \mathrm{mg} / \mathrm{dL}$

$1997-2003$

$2004-2009$

$2010-2017$

Bilirubin $>10 \mathrm{mg} / \mathrm{dL}$

$1997-2003$

$2004-2009$

$2010-2017$

Creatinine $>2 \mathrm{x}$ baseline

$1997-2003$

$2004-2009$

$2010-2017$

Infections (1=1,502)

Gram-negative bacteremia

$1997-2003$

$2004-2009$

$2010-2017$

Invasive fungal infection

$1997-2003$

$2004-2009$

2010 - 2017

CMV antigenemia ${ }^{\mathrm{b}}$

$1997-2003$

$2004-2009$

$2010-2017$

CMV disease ${ }^{\mathrm{b}}$

$1997-2003$

2004-2009

$2010-2017$

1.0

$0.28(0.18-0.42)<0.0001$

$0.22(0.14-0.35)<0.0001$

OR: odds ratio; HR: hazard ratio; $\mathrm{CI}$ : confidence interval; MM: multiple myeloma; $\mathrm{AML}$ acute myeloid leukemia; R: recipient; D: donor; CMV: cytomegalovirus; HCT: hematopoietic cell transplantation; HCT-CI:hematopoietic cell transplantation comorbidity index. ${ }^{a}$ Adjusted for transplantation center; treatment type (protocol, treatment plan); age ( $\leq 49,50-59,60+$ years); disease risk group (low,standard, high); MM diagnosis; AML diagnosis; CMV (R- and D-, R+ or D+); donor relation (related, unrelated); sex mismatch (female to male, others); prior HCT (no,yes); allele mismatch (no,yes); and HCT-CI $\left(0,1-2,3, \geq 4\right.$, missing). ${ }^{\mathrm{b}} \mathrm{CMV}$ endpoints evaluated only among seropositive recipients at $\mathrm{HCT}$ ( $\mathrm{n}=911$ for multivariate analysis).

fungal therapy for patients with pulmonary nodules ${ }^{33}$ and the adoption of pre-emptive antiviral therapy driven by highly sensitive PCR-based CMV DNA diagnostic testing of blood samples. ${ }^{14-16}$

Reduction in the incidences of acute GvHD in our later patient cohorts were due, in part, to the increasing use of sirolimus as a component of GvHD prophylaxis for unrelated recipients 6,8 and the adoption of ursodiol to prevent cholestasis and hyperbilirubinemia. ${ }^{4}$ In addition to our data here documenting the beneficial effect of sirolimus, we recently reported the results of a randomized phase III trial showing that the addition of sirolimus to the standard prophylactic regimen of MMF and cyclosporine in unrelated recipients reduced the day 100 cumulative incidence of grades $2-4$ acute GvHD (26\% vs. $52 \%$ ), resulting in significantly reduced use of steroids and markedly improved 1-year NRM, PFS, and OS. ${ }^{8}$ While there was no difference in chronic GvHD between the two groups, patients affected by chronic GvHD in the triple-drug group had a trend towards lower NRM after 1 year compared with those in the standard group (4\% in triple-drug group vs. $15 \%$ in the standard group). Ursodiol use, at a dose of $12 \mathrm{mg} / \mathrm{kg} / \mathrm{day}$ 

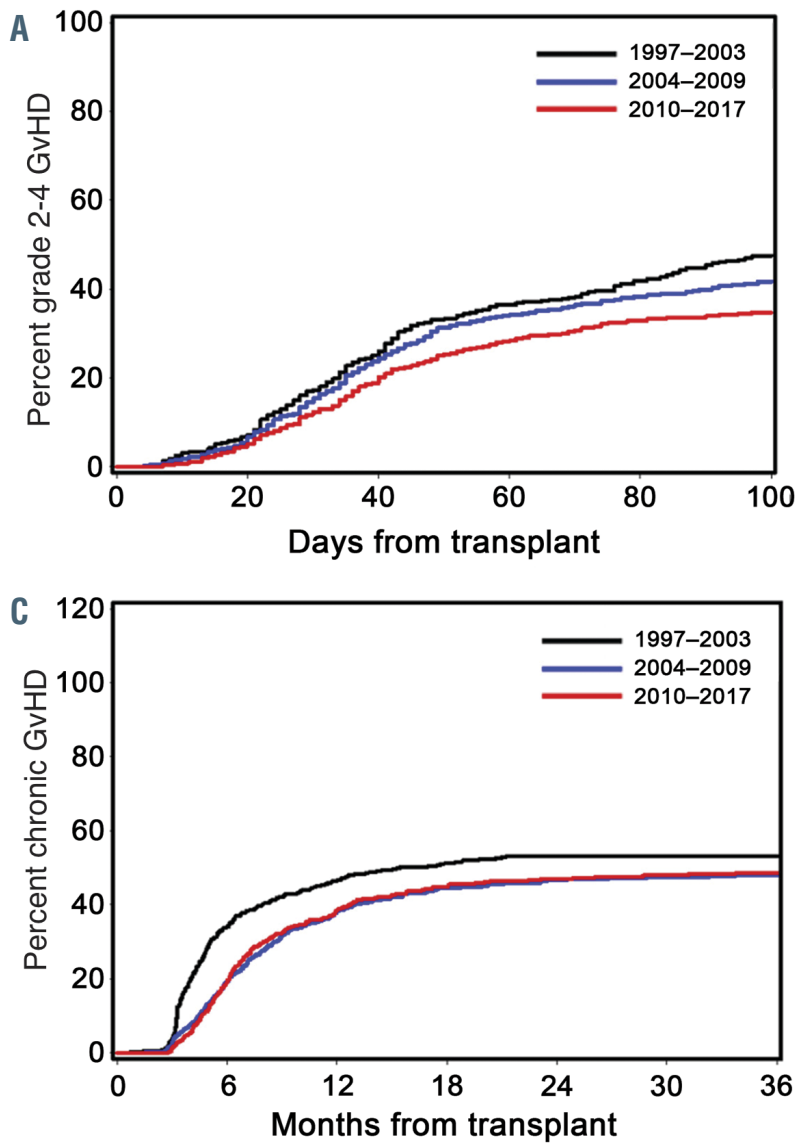

starting on the day before HCT, significantly reduced the incidences of stages 2-4 liver and intestinal acute GvHD and grades 3-4 acute GvHD, and improved both 1-year OS and NRM. ${ }^{4}$

The overall incidence of relapse was significantly lower during 2010-2017 compared to earlier time periods. This corresponded both with an increasing use of higher TBI doses (3-4.5 Gy) for patients who did not receive preceding myelosuppressive chemotherapy, and with an increasing proportion of patients who underwent HCT with diseases at a lower risk of relapse. The majority of our patients who received increased TBI dosing carried a diagnosis of AML, MDS, or a myeloproliferative neoplasm based on a prospective TBI dose escalation study showing a reduction in relapse with higher TBI dosing in MDS/MPN patients who had not had previous myelosuppressive (induction-type) chemotherapy. ${ }^{34}$ The lower grade MDS/MPN patients benefitted by increasing the TBI dose to $3 \mathrm{~Gy}$ whereas the patients with excess blasts or a history of CMML benefitted by increasing the TBI dose to $4.5 \mathrm{~Gy}$. Based on the findings in the low grade MDS patients, the TBI dose was increased to 3 Gy in AML patients who had not received induction chemotherapy in the preceding 3-6 months or had a previous allogeneic transplant from a different donor. In a sub-analysis, we found no significant change in the rate of relapse in the subset of AML patients who underwent HCT in CR1/CR2, a finding that has also been noted in AML patients who predominantly received high-intensity conditioning prior to $\mathrm{HCT} .{ }^{35}$ While we also noted an increase in the number of AML patients in CR1/CR2 with MRD at the time of non-myeloablative HCT, we recognize that

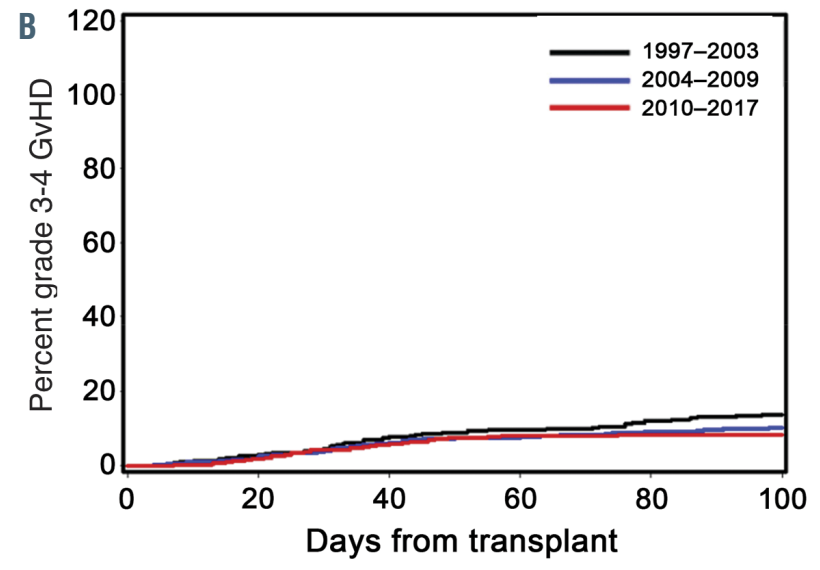

Figure 2. Adjusted cumulative incidence rates of acute and chronic graft-versus-host disease by era of transplant. (A) Grades 2-4 acute graft-versus-host disease (GVHD), (B) grades 3-4 acute GvHD, and (C) chronic GvHD. Era of transplant: 1997-2003 (black line), 2004-2009 (blue line), and 2010-2017 (red line).

the detection of MRD and its association with disease risk-stratification relative to HCT evolved over our time period of analysis and may have affected the selection of patients in our cohort who underwent HCT after nonmyeloablative conditioning versus receiving other therapies.

The overall incidence of relapse-related mortality trended toward improvement for our 2004-2009 and 2010 2017 patient cohorts. Hypomethylating agents, in particular, gained increasing use for the treatment of relapsed myeloid malignancies during our later time periods, ${ }^{36,37}$ and are likely a contributor to the observed modest attenuation of relapse-related mortality. More recently, there has been an expansion in the treatment armamentarium for relapsed disease including ibrutinib, venetoclax, and enasidinib, ${ }^{38-40}$ checkpoint inhibitors, ${ }^{41,42}$ tyrosine kinase inhibitors, ${ }^{43}$ and monoclonal antibodies. ${ }^{44,45}$ Many of these agents were used too infrequently to have influenced the outcomes reported here, but we anticipate that their use will increase and may lead to further reduction in mortality after relapse.

Interestingly, we found that the significant improvements in OS, PFS, rate of grades $2-4$ acute GvHD, and in the incidence of infectious complications continued to occur over our total period of analysis. However, the statistically significant improvements in other clinical outcomes were limited to particular eras. For example, NRM, relapse-related mortality, rate of grades 3-4 acute GvHD, rate of chronic GvHD, and the incidences of liver and kidney injury improved significantly only when 2004- 2009 was compared to 1997-2003; the rate of relapse or progression improved significantly only in the most recent 
Table 4. Summary of changes in clinical practice that affected non-relapse mortality over time.

Increased use of topically-active GI glucocorticoids for patient with GI acute GvHD

Decreased use of systemic glucocorticoids for patients with acute GvHD

Addition of sirolimus to $\mathrm{Cl}$ and MMF for GvHD prophylaxis

Increased use of ursodiol to prevent cholestasis and hyperbilirubinemia

Increased use of fluoroquinolones as antibacterial prophylaxis in neutropenic patients

Increased use of mold-active triazoles as antifungal prophylaxis

Increased use of empiric antifungal therapy for patients with pulmonary nodules

Increasing use of pre-emptive antiviral therapy for CMV viremia

NRM: non-relapse mortality; GI: gastrointestinal; GvHD: graft-versus-host disease; CI: calcineurin inhibitor; MMF: mycophenolate mofetil; CMV: cytomegalovirus.

era. While those outcomes which did not show statistical improvements in the most recent era had hazard ratios that trended toward improvement, it is likely that the continual improvement in OS and PFS had different predominant components at different times: improvements in NRM, relapse-related mortality, and organ toxicity contributing earlier (between 1997-2003 and 2004-2009) and improvement in the rate of relapse contributing later (between 2004-2009 and 2010 -2017).

The present findings are similar to those of prior analyses which predominantly included patients who received high-intensity conditioning. ${ }^{35,46,47}$ It is notable, however, that in these prior studies the increased use of lower-intensity conditioning regimens and granulocyte colony-stimulating factor-mobilized peripheral blood stem cell (PBSC) grafts were cited as prominent reasons for the improved outcomes - particularly reductions in NRM. The homogeneous nature of the current patient population, with all patients receiving lower-intensity conditioning regimens and HLA-matched PBSC grafts, allowed us to more independently appraise the influence of changes in supportive care that are critical for successful outcomes after HCT.

In conclusion, we show that improvements in supportive care after HCT with non-myeloablative conditioning for patients with advanced hematologic malignancies during the past two decades have yielded higher rates of overall survival and PFS and lower risks of NRM, grades 2-4 acute GvHD, and chronic GvHD. During this period, the age of patients and burden of comorbidity at the time of HCT has increased, and use of unrelated donors has also increased, thereby making allogeneic HCT more widely available for patients with otherwise incurable hematologic malignancies. These results should encourage the referral of elderly and medically infirm younger patients with hematologic malignancies for evaluation at a transplant center.

\section{Disclosures}

No conflicts of interest to disclose.

\section{Contributions}

$J P C, B E S, N G, G M c D, R S$ and BMS contributed to the conception and design; $R S$ and BMS secured financial support; $R S$ and $B M S$ provided administrative support; $B G, M L S, T R C, J S$, $G-N F, M B M, M B, B B, F S, A A L, P H, E D A, S L P, R T M, W B$, $J A, J A G, G O, A M Y, K H, W J H, D G M, M M, P J M, M E D F$, GEG, $A E W, H J D, B L S, G B M c D, R S$ and $B M S$ provided study materials or patients; JPC, BG, MLS, TRC, JS, G-NF, MBM, $M B, B B, F S, A A L, P H, E D A, S L P, R T M, W B, J A, J A G, G O$, $A M Y, K H, W J H, D G M, M M, P J M, M E D F, G E G, A E W$, $H J D, B L S, G B M c D, R S$ and BMS collected and assembled data; JPC, BES, NG, GMcD, RS and BMS analyzed and interpreted data; all authors contributed to the writing and final apporval of the manuscript.

\section{Acknowledgments}

The authors are grateful to the research nurses and data coordinators who implemented the study protocols; to the many physicians, nurses, physician assistants, nurse practitioners, pharmacists, and support staff who cared for our patients; and to the patients who allowed us to care for them and participated in our research. We are deeply indebted to Helen S. Crawford for assistance in preparing the manuscript, tables, and figures. The content is solely the responsibility of the authors and does not represent the official views of the institutions who provided funding support.

\section{Funding}

Research reported in this publication was supported by P01 HL36444, P01 HL122173, and T32 HL007093 from the NHLBI; P01 CA078902 and P30 CA015704 from the NCI and NIH; and grants from the Laura Landro Solomon Endowment Fund and Gabrielle's Angels Foundation.

\section{References}

1. Storb R, Gyurkocza B, Storer BE, et al. Graft-versus-host disease and graft-versustumor effects after allogeneic hematopoietic cell transplantation. J Clin Oncol. 2013; 31(12):1530-1538.

2. Mielcarek M, Storer BE, Boeckh M, et al. Initial therapy of acute graft-versus-host disease with low-dose prednisone does not compromise patient outcomes. Blood. 2009;113(13):2888-2894.

3. Hockenbery DM, Cruickshank S, Rodell $\mathrm{TC}$, et al. A randomized, placebo-controlled trial of oral beclomethasone dipropionate as a prednisone-sparing therapy for gastrointestinal graft-versus-host disease. Blood. 2007;109(10):4557-4563.

4. Ruutu T, Eriksson B, Remes $\mathrm{K}$, et al. Ursodeoxycholic acid for the prevention of hepatic complications in allogeneic stem cell transplantation. Blood. 2002; 100(6):1977-1983.

5. Fried RH, Murakami CS, Fisher LD, Willson RA, Sullivan KM, McDonald GB. Ursodeoxycholic acid treatment of refractory chronic graft-versus-host disease of the liver. Ann Intern Med. 1992;116(8):624-629.

6. Kornblit B, Maloney DG, Storer BE, et al. A randomized phase II trial of tacrolimus, mycophenolate mofetil and sirolimus after non-myeloablative unrelated donor trans- plantation. Haematologica. 2014;99(10) 1624-1631

7. Armand P, Kim HT, Sainvil MM, et al. The addition of sirolimus to the graft-versushost disease prophylaxis regimen in reduced intensity allogeneic stem cell transplantation for lymphoma: a multicentre randomized trial. Br J Haematol. 2016; 173(1):96-104.

8. Sandmaier BM, Kornblit B, Storer BE, et al. Addition of sirolimus to standard cyclosporine plus mycophenolate mofetilbased graft-versus-host disease prophylaxis for patients after unrelated non-myeloablative haemopoietic stem cell transplantation: a multicentre, randomised, phase 3 
trial. Lancet Haematol. 2019;6(8):e409e418.

9. Gafter-Gvili A, Fraser A, Paul M, van de Wetering M, Kremer L, Leibovici L. Antibiotic prophylaxis for bacterial infections in afebrile neutropenic patients following chemotherapy. Cochrane Database Syst Rev. 2005(4):CD004386.

10. Gafter-Gvili A, Fraser A, Paul M, et al. Antibiotic prophylaxis for bacterial infections in afebrile neutropenic patients following chemotherapy. Cochrane Database Syst Rev. 2012;1:CD004386.

11. Reuter S, Kern WV, Sigge A, et al. Impact of fluoroquinolone prophylaxis on reduced infection-related mortality among patients with neutropenia and hematologic malignancies. Clin Infect Dis. 2005:40(8):10871093.

12. Robenshtok E, Gafter-Gvili A, Goldberg E, et al. Antifungal prophylaxis in cancer patients after chemotherapy or hematopoietic stem-cell transplantation: systematic review and meta-analysis. J Clin Oncol. 2007;25(34):5471-5489.

13. Ethier MC, Science M, Beyene J, Briel M, Lehrnbecher T, Sung L. Mould-active compared with fluconazole prophylaxis to prevent invasive fungal diseases in cancer patients receiving chemotherapy or haematopoietic stem-cell transplantation: a systematic review and meta-analysis of randomised controlled trials. Br J Cancer. 2012;106(10):1626-1637.

14. Peggs KS, Preiser W, Kottaridis PD, et al. Extended routine polymerase chain reaction surveillance and pre-emptive antiviral therapy for cytomegalovirus after allogeneic transplantation. $\mathrm{Br} J$ Haematol. 2000;111(3):782-790.

15. Mori T, Okamoto S, Watanabe $\mathrm{R}$, et al. Dose-adjusted preemptive therapy for cytomegalovirus disease based on real-time polymerase chain reaction after allogeneic hematopoietic stem cell transplantation. Bone Marrow Transplant. 2002;29(9):777782.

16. Reusser P, Einsele H, Lee $J$, et al. Randomized multicenter trial of foscarnet versus ganciclovir for preemptive therapy of cytomegalovirus infection after allogeneic stem cell transplantation. Blood. 2002;99(4):1159-1164.

17. Sorror ML, Maris MB, Storb R, et al. Hematopoietic cell transplantation (HCT)specific comorbidity index: a new tool for risk assessment before allogeneic HCT. Blood. 2005;106(8):2912-2919.

18. Filipovich AH, Weisdorf D, Pavletic S, et al. National Institutes of Health consensus development project on criteria for clinical trials in chronic graft-versus-host disease: I. Diagnosis and staging working group report. Biol Blood Marrow Transplant. 2005;11(12):945-956.

19. Przepiorka D, Weisdorf D, Martin P, et al. 1994 Consensus Conference on Acute GVHD Grading. Bone Marrow Transplant. 1995;15(6):825-828.

20. Kahl C, Storer BE, Sandmaier BM, et al. Relapse risk in patients with malignant diseases given allogeneic hematopoietic cell transplantation after nonmyeloablative conditioning. Blood. 2007;110(7):27442748.
21. Hingorani SR, Guthrie K, Batchelder A, et al. Acute renal failure after myeloablative hematopoietic cell transplant: incidence and risk factors. Kidney Int. 2005;67(1):272277.

22. Boeckh $M$, Huang $M$, Ferrenberg J, et al. Optimization of quantitative detection of cytomegalovirus DNA in plasma by realtime PCR. J Clin Microbiol. 2004; 42(3):1142-1148.

23. Ljungman P, Griffiths P, Paya C. Definitions of cytomegalovirus infection and disease in transplant recipients. Clin Infect Dis. 2002;34(8):1094-1097.

24. Chien JW, Boeckh MJ, Hansen JA, Clark JG Lipopolysaccharide binding protein promoter variants influence the risk for gramnegative bacteremia and mortality after allogeneic hematopoietic cell transplantation. Blood. 2008;111(4):2462-2469.

25. De Pauw B, Walsh TJ, Donnelly JP, et al. Revised definitions of invasive fungal disease from the European Organization for Research and Treatment of Cancer/Invasive Fungal Infections Cooperative Group and the National Institute of Allergy and Infectious Diseases Mycoses Study Group (EORTC/MSG) Consensus Group. Clin Infect Dis. 2008:46(12):1813-1821.

26. Gooley TA, Leisenring W, Crowley J, Storer $\mathrm{BE}$. Estimation of failure probabilities in the presence of competing risks: new representations of old estimators. Stat Med. 1999;18(6):695-706.

27. Storer BE, Gooley TA, Jones MP. Adjusted estimates for time-to-event endpoints. Lifetime Data Anal. 2008;14(4):484-495.

28. Ljungman P, Aschan J, Lewensohn-Fuchs I, et al. Results of different strategies for reducing cytomegalovirus-associated mortality in allogeneic stem cell transplant recipients. Transplantation. 1998; 66(10):1330-1334.

29. Krishnan A, Pasquini MC, Logan B, et al. Autologous haemopoietic stem-cell transplantation followed by allogeneic or autologous haemopoietic stem-cell transplantation in patients with multiple myeloma (BMT CTN 0102): a phase 3 biological assignment trial. Lancet Oncol. 2011;12 (13):1195-1203

30. Gyurkocza B, Storb R, Chauncey TR, Maloney DG, Storer BE, Sandmaier BM. Second allogeneic hematopoietic cell transplantation for relapse after first allografts. Leuk Lymphoma. 2019;60(7):17581766.

31. Greenberg PL, Tuechier H, Schanz J, et al. Revised international prognostic scoring system for myelodysplastic syndromes. Blood. 2012;120(12):2454-2465.

32. Koreth J, Pidaia J, Perez WS, et al. Role of reduced-intensity conditioning allogeneic hematopoietic stem-cell transplantation in older patients with de novo myelodysplastic syndrome: an international collaborative decision analysis. J Clin Oncol. 2013;31 (21):2662-2670

33. Dignan FL, Evans SO, Ethell ME, et al. An early CT-diagnosis-based treatment strategy for invasive fungal infection in allogeneic transplant recipients using caspofungin first line: an effective strategy with low mortality. Bone Marrow Transplant. 2009;
44(1):51-56

34. Monaco F, Scott BL, Chauncey TR, et al. Total body irradiation dose escalation decrases risk of progression and graft rejection after hematopoietic cell transplantation for myelodysplastic syndromes or myeloproliferative neoplasms. Haematologica. 2019;104(6):1221-1229.

35. Canaani J, Beohou E, Labopin M, et al. Trends in patient outcome over the past two decades following allogeneic stem cell transplantation for acute myeloid leukaemia: an ALWP/EBMT analysis. J Intern Med. 2019;285(4):407-418.

36. Graef T, Kuendgen A, Fenk R, Zohren F, Haas R, Kobbe G. Successful treatment of relapsed AML after allogeneic stem cell transplantation with azacitidine. Leuk Res. 2007;31(2):257-259.

37. Platzbecker U, Wermke M, Radke J, et al Azacitidine for treatment of imminent relapse in MDS or AML patients after allogeneic HSCT: results of the RELAZA trial. Leukemia. 2012;26(3):381-389.

38. Ryan CE, Sahaf B, Logan AC, et al Ibrutinib efficacy and tolerability in patients with relapsed chronic lymphocytic leukemia following allogeneic HCT. Blood. 2016;128(25):2899-2908.

39. Stein EM, DiNardo CD, Pollyea DA, et al. Enasidenib in mutant IDH2 relapsed or refractory acute myeloid leukemia. Blood. 2017;130(6):722-731.

40. Konopleva M, Pollyea DA, Potluri J, et al Efficacy and biological correlates of response in a phase II study of venetoclax monotherapy in patients with acute myelogenous leukemia. Cancer Discov. 2016; 6(10):1106-1117

41. Davids MS, Kim HT, Bachireddy P, et al Ipilimumab for patients with relapse after allogeneic transplantation. N Engl J Med. 2016;375(2):143-153.

42. Haverkos BM, Abbott D, Hamadani M, et al. PD-1 blockade for relapsed lymphoma post-allogeneic hematopoietic cell transplant: high response rate but frequent GVHD. Blood. 2017;130(2):221-228.

43. Metzelder SK, Schroeder T, Finck A, et al High activity of sorafenib in FLT3-ITD-positive acute myeloid leukemia synergizes with allo-immune effects to induce sustained responses. Leukemia. 2012;26(11): 2353-2359.

44. Ueda M, de Lima M, Caimi $P$, et al Concurrent blinatumomab and donor lymphocyte infusions for treatment of relapsed pre-B-cell ALL after allogeneic hematopoietic cell transplant. Bone Marrow Transplant. 2016;51(9):1253-1255.

45. Kantarjian HM, DeAngelo DJ, Stelljes M, et al. Inotuzumab ozogamicin versus standard therapy for acute lymphoblastic leukemia. N Engl J Med. 2016;375(8):740-753.

46. Hahn T, McCarthy PL, Jr., Hassebroek A, et al. Significant improvement in survival after allogeneic hematopoietic cell transplantation during a period of significantly increased use, older recipient age, and use of unrelated donors. J Clin Oncol. 2013; 31(19):2437-2449

47. Gooley TA, Chien JW, Pergam SA, et al. Reduced mortality after allogeneic hematopoietic-cell transplantation. N Engl J Med. 2010;363(22):2091-2101. 